\title{
Characteristics and properties of polyimide/vanadium oxide hybrid membranes
}

\author{
Mei-Hui Tsai ${ }^{\text {**, Shih-Liang Huang }}{ }^{\mathrm{a}}$, Pei-Jyun Chen ${ }^{\mathrm{a}}$, Pei-Chun Chiang ${ }^{\mathrm{b}}$, \\ Dong-Sen Chen ${ }^{\mathrm{a}}$, Horng-Hwa Luc ${ }^{\mathrm{c}}$, Wei-Ming Chiu ${ }^{\mathrm{a}}$, Juo-Chen Chen ${ }^{\mathrm{d}}$, \\ Hsu-Tung $\mathrm{Lu}^{\mathrm{a}}$ \\ ${ }^{a}$ Department of Chemical and Materials Engineering, National Chin-Yi University of Technology, \\ Taichung 411 Taiwan, R. O. C. \\ Tel. +886(4)23924505-7510; Fax+886(4)23926617; email: tsaimh@mail.ncut.edu.tw \\ ${ }^{b}$ Department of Materials Science and Engineering, MingDao University, ChangHua 523 Taiwan, R. O. C. \\ ${ }^{c}$ Department of Mechanical Engineering, National Chin-Yi University of Technology, \\ Taichung 411 Taiwan, R. O. C. \\ ${ }^{d}$ Department of Electronic Engineering, National Chin-Yi University of Technology, \\ Taichung 411 Taiwan, R. O. C.
}

Received 15 August 2007; accepted revised 1 October 2007

\begin{abstract}
A series of polyimide/vanadium pentoxide $\left(\mathrm{PI} / \mathrm{V}_{2} \mathrm{O}_{5}\right)$ hybrid film has been successfully fabricated through the in situ formation of $\mathrm{V}_{2} \mathrm{O}_{5}$ within a polymer matrix by sol-gel process. The polyamic acid (PAA) is prepared from 4,4'-diaminodiphenyl ether (ODA) and 3,3',4,4'-benzophenonetetracarboxylic anhydride (BTDA) in $N$-methylpyrrolidinone (NMP) solvent. Then different amounts of Bis-(2,4-pentanedionato) vanadium oxide are incorporated into polyamic acid (PAA) matrix, respectively and then thermally imidized to form $\mathrm{PI} / \mathrm{V}_{2} \mathrm{O}_{5}$ hybrid membranes. The imidization temperature and time are optimized by FTIR measurements through the observation of $\mathrm{V}_{2} \mathrm{O}_{5}$ absorption peak. The influence of $\mathrm{V}_{2} \mathrm{O}_{5}$ content on the thermal stability, morphology and mechanical properties of $\mathrm{PI} / \mathrm{V}_{2} \mathrm{O}_{5}$ hybrid films are studied.
\end{abstract}

Keywords: Polyimide; Vanadium oxide; Hybrid; Sol-gel method

*Corresponding author.

Presented at the Fourth Conference of Aseanian Membrane Society (AMS 4), 16-18 August 2007, Taipei, Taiwan. 


\section{Introduction}

The preparation, characterization and applications of polymer/inorganic hybrid materials have become a fast expanding area of research in material science. The major driving forces behind the intense activities in this area are the new and different properties of the nanocomposite for the traditional macroscale composites and conventional materials do not have. Recently, new hybrid materials are prepared through chemical bonding formation between molecules, such as covalent or hydrogen or ionic bonds. From then on, this new hybrid material can conquer obvious phase separation between polymer and inorganic and possess mutual characteristics complementing each other.

The sol-gel method has been widely used to synthesize polymer/inorganic nanocomposite. There are many polyimide/inorganic hybrid materials prepared and applied in electronic and automobile industry due to their superior mechanical properties, thermal stability and low dielectric constants.

Vanadium oxide and their derivative compounds have attracted much attention due to their special physical and chemical properties, and potential applications in various fields such as catalysts [1], lithium-ion batteries [2], electrochromic $[3,4]$, and chemical sensors $[5,6]$. This material possesses an outstanding structural versatility and can be manufactured into various one-dimensional (1D) nanostructures that have many useful physicochemical properties. In addition, the nanostructured vanadium oxide shows a good potential for completely novel applications such as nanoactuators [7] and nonlinear optical limiters [8].

The vanadium pentoxide $\left(\mathrm{V}_{2} \mathrm{O}_{5}\right)$ films can be deposited by several techniques, such as reactive magnetron sputtering, ion beam evaporation, wet chemical coating and sol-gel deposition process [9-11]. While, the sol-gel method of preparation of metal oxide in the polyimide has been well-documented [12-16]. The organic/ inorganic sol-gel methodology offers the advantages of large area deposition with controlled-film microstructure and production of films containing multiple cations [17]. However the inferior thermal stability of organics may restrict a composites application in the electronic and optoelectronic industries. Meanwhile, PI and hybrids are a well-known thermally stable polymer and mechanical stable for the high reliability of electronic and photoelectronic applications [18-20].

In this study, the $\mathrm{PI} / \mathrm{V}_{2} \mathrm{O}_{5}$ hybrid films are prepared by sol-gel method. The $\mathrm{VO}(\mathrm{acac})_{2}$ is introduced to the poly(amic acid) PI precursors, the composite is thermally imidized to form $\mathrm{PI} / \mathrm{V}_{2} \mathrm{O}_{5}$ hybrid films. The effect of the $\mathrm{V}_{2} \mathrm{O}_{5}$ content and PI structure on the thermal, mechanical and morphology characteristics of the hybrid films are investigated.

\section{Experiment}

\subsection{Materials}

3,3',4,4'-Benzophenonetetracarboxylicdianhydride (BTDA) from ACORS company is purified by recrystallization from acetic anhydride and then dried in a vacuum oven at $125^{\circ} \mathrm{C}$ overnight. 4,4'-diamino-diphenyl ether (ODA) from Lancaster is vacuum-dried for $3 \mathrm{~h}$ at $120^{\circ} \mathrm{C}$ prior to use. $\mathrm{N}$-methyl-2-pyrrolidinone (NMP) from Tedia Company is dried over molecular sieves. (Bis(2,4-pentanedionato)vanadium-oxide) from TCI company is used as supplied.

\subsection{Preparation of the $\mathrm{PI} / \mathrm{V}_{2} \mathrm{O}_{5}$ hybrid films}

The procedures for preparing poly(amic acid) (PAA) and $\mathrm{PI} / \mathrm{V}_{2} \mathrm{O}_{5}$ hybrid film are shown in Fig. 1. The PAA solution is made by reacting equal amounts of BTDA and ODA in NMP solvent under a nitrogen atmosphere. Then the different amount of $\mathrm{VO}(\mathrm{acac})_{2}$ is added into 


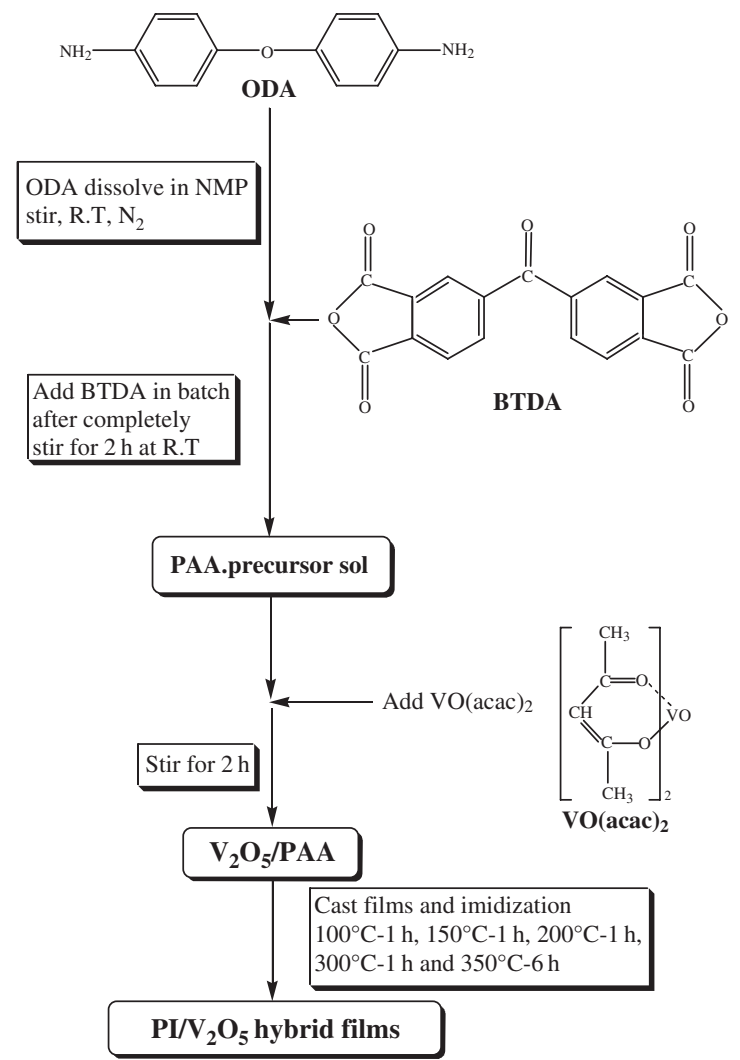

Fig. 1. The preparation procedures of $\mathrm{PI} / \mathrm{V}_{2} \mathrm{O}_{5}$ hybrid films.

PAA to obtain PAA/ $\mathrm{V}_{2} \mathrm{O}_{5}$ precursor. The PAA/ $\mathrm{V}_{2} \mathrm{O}_{5}$ mixture is cast on glass plates and then step-heated in an oven through optimized imidization temperatures $350^{\circ} \mathrm{C}$ for $6 \mathrm{~h}$. Sample abbreviation is named as $\mathrm{PI} / \mathrm{V}_{2} \mathrm{O}_{5}-\mathrm{X} \%$. $\mathrm{X}$ denotes the weight percentage of $\mathrm{V}_{2} \mathrm{O}_{5}$ within polymer matrix.

\subsection{Measurements}

The functional groups and absorption peaks are measured with fourier transform infrared spectrophotometer (FTIR; Nicolet PROTÉGÉ460). The decomposition temperature of the hybrid film is detected with Thermogravimetric analyzer (TGA; TGA-Q500) at a heating rate of $20^{\circ} \mathrm{C} \mathrm{min}^{-1}$ from 100 to $800^{\circ} \mathrm{C}$ under nitrogen atmosphere. The storage modulus and $T_{\mathrm{g}}$ are measured by dynamic mechanical analyzer (DMA; DMA 2980) at a heating rate of $3^{\circ} \mathrm{C}$ $\mathrm{min}^{-1}$ from 100 to $425^{\circ} \mathrm{C}$. The cross-section morphology is performed using a scanning electron microscopy (SEM; TESCAN 5136LS). $\mathrm{X}$-ray diffraction (XRD) pattern is obtained with a MacScience MXP model using graphite-filtered $\mathrm{Cu}-\mathrm{K} \alpha$ radiation. The diffraction pattern is taken at room temperature in the range of $10<\theta<60^{\circ}$ at the scan rate of $6^{\circ} \mathrm{min}^{-1}$.

\section{Results and discussion}

The optimum preparation of membrane is described as following: first, the coated PAA/ $\mathrm{V}_{2} \mathrm{O}_{5}$ precursor is heated gradually at 100, 150, 200 and $300^{\circ} \mathrm{C}$ for each $1 \mathrm{~h}$ respectively and then further heated for $6 \mathrm{~h}$ at $350^{\circ} \mathrm{C}$.

FTIR is used to identify the structure of PI/ $\mathrm{V}_{2} \mathrm{O}_{5}$ hybrid film. Fig. 2 displays the FTIR absorption spectra of pure PI and $\mathrm{PI} / \mathrm{V}_{2} \mathrm{O}_{5}$ hybrid film with various $\mathrm{V}_{2} \mathrm{O}_{5}$ content and are recorded between 4000 and $400 \mathrm{~cm}^{-1}$. The characteristic absorption peak are $1780 \mathrm{~cm}^{-1}$ $\left(\mathrm{C}=\mathrm{O}\right.$, asymmetric stretch), $1720 \mathrm{~cm}^{-1}(\mathrm{C}=\mathrm{O}$, symmetric stretch), $1380 \mathrm{~cm}^{-1}$ of imide group (C-N) and 700-430 $\mathrm{cm}^{-1}$ (V-O-V stretching) are clearly presented. While hybrid film with

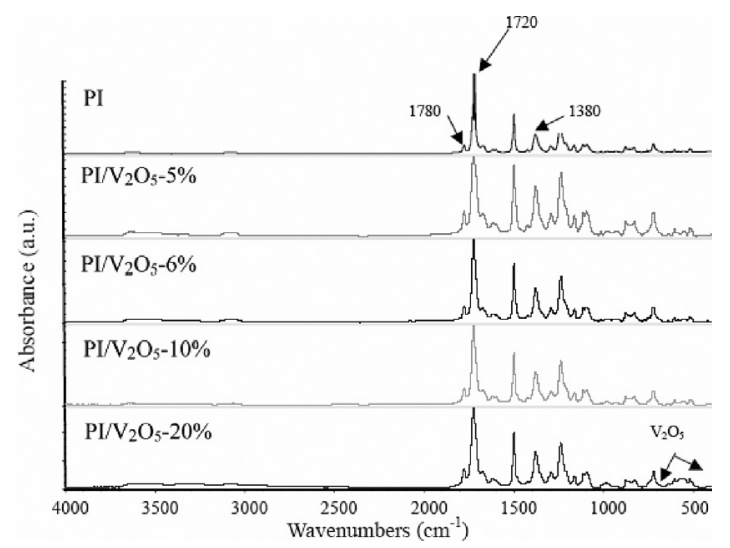

Fig. 2. FTIR spectra of $\mathrm{PI} / \mathrm{V}_{2} \mathrm{O}_{5}$ hybrid film with different $\mathrm{V}_{2} \mathrm{O}_{5}$ content. 


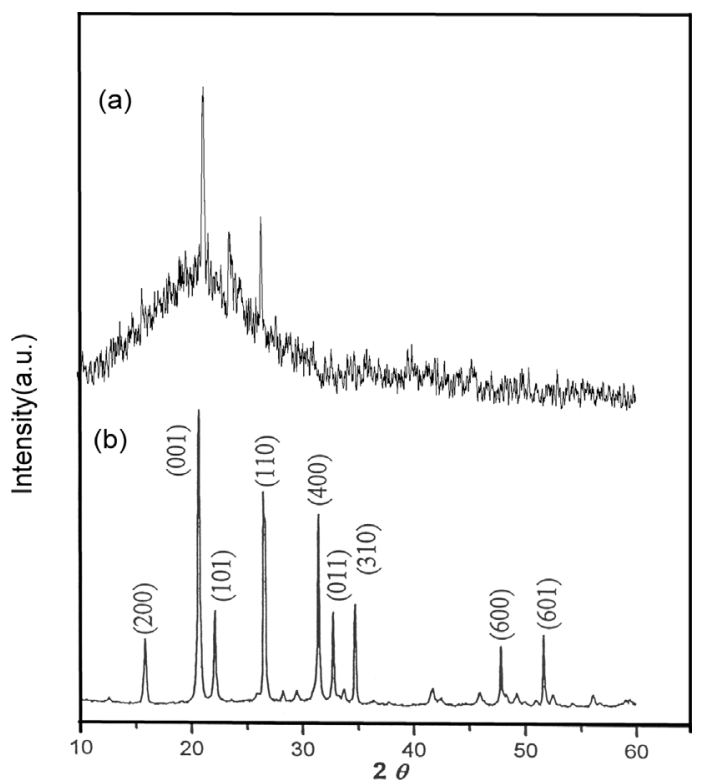

Fig. 3. X-ray of (a) $\mathrm{PI} / \mathrm{V}_{2} \mathrm{O}_{5} \quad 10 \%$ hybrid film and (b) standard $\mathrm{V}_{2} \mathrm{O}_{5}$.

high $\mathrm{V}_{2} \mathrm{O}_{5}$ content $(20$ wt.\%) has wide absorption peaks in the range of $650-450 \mathrm{~cm}^{-1}$.

Owing to the ODA and BTDA with non-linear and amorphous structure, respectively, the X-ray spectra of BTDA/ODA hybrids cannot present obviously diffraction peaks as presented in Fig. 3. Therefore, the all hybrid films show amorphous properties. While the three peaks of $\mathrm{PI} / \mathrm{V}_{2} \mathrm{O}_{5}$ hybrid film can be depicted that there are three (001), (101), (110) crystalline peaks presented and hence can be used to predict the existence of $\mathrm{V}_{2} \mathrm{O}_{5}$.

Fig. 4 shows the cross-section images of $\mathrm{PI} / \mathrm{V}_{2} \mathrm{O}_{5}$ hybrid films with SEM. According to Fig. $4 \mathrm{a}$, the hybrid film with $1 \% \mathrm{~V}_{2} \mathrm{O}_{5}$ is homogeneous and smooth as compared with other content of hybrid film. From Fig. $4 a-e$, it can be seen that the cross-section surface roughness increases as increasing the content of $\mathrm{V}_{2} \mathrm{O}_{5}$ in PI matrix. While the domain size of the $\mathrm{V}_{2} \mathrm{O}_{5}$ cannot be estimated with SEM analysis.

The thermal stability of the hybrid films are listed in Table 1. The dynamic thermogravimetric
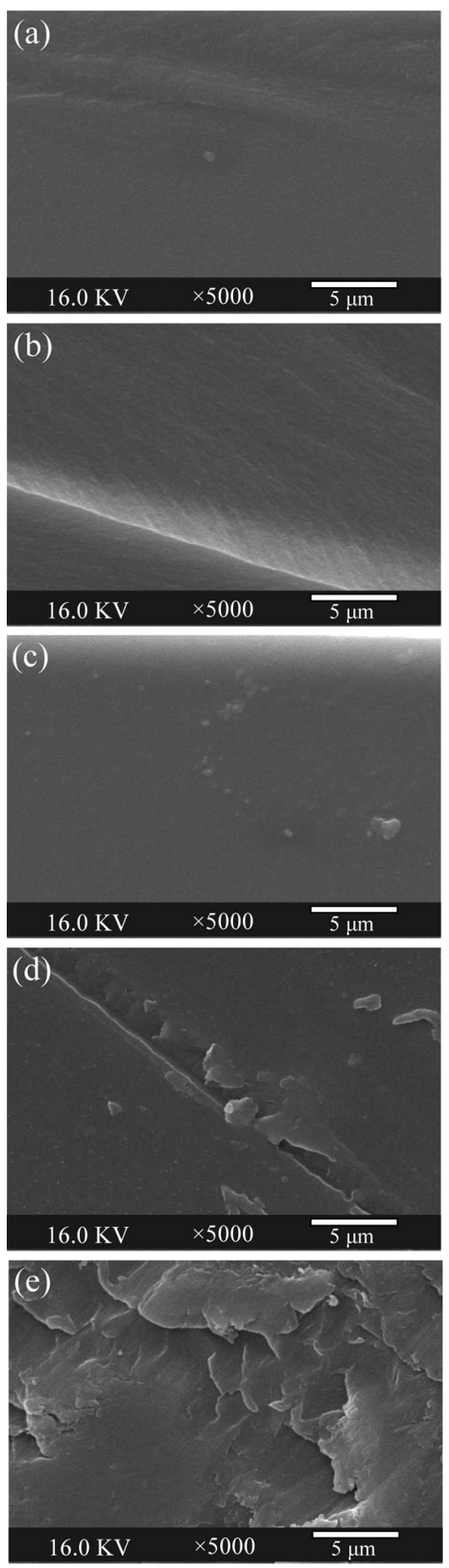

Fig. 4. SEM photograph of $\mathrm{PI} / \mathrm{V}_{2} \mathrm{O}_{5}$ hybrid film with different $\mathrm{V}_{2} \mathrm{O}_{5}$ content. (a) $1 \%$, (b) $2 \%$, (c) $3 \%$, (d) $4 \%$ and (e) $5 \%$. 
Table 1

Thermal weight loss of $\mathrm{PI} / \mathrm{V}_{2} \mathrm{O}_{5}$ hybrid films

\begin{tabular}{lll}
\hline $\begin{array}{l}\text { Compound } \\
\text { code }\end{array}$ & $\begin{array}{l}\text { Decomposed } \\
\text { temperature }\end{array}$ & $\begin{array}{l}800^{\circ} \mathrm{C} \text { Char } \\
\text { yield }(\%)\end{array}$ \\
\hline $\mathrm{PI}$ & 580.26 & 59.72 \\
$\mathrm{PI} / \mathrm{V}_{2} \mathrm{O}_{5}-1 \%$ & 480.74 & 61.49 \\
$\mathrm{PI} / \mathrm{V}_{2} \mathrm{O}_{5}-2 \%$ & 478.31 & 60.77 \\
$\mathrm{PI} / \mathrm{V}_{2} \mathrm{O}_{5}-6 \%$ & 467.39 & 60.85 \\
\hline
\end{tabular}

${ }^{\mathrm{a}}$ Temperature at $5 \%$ weight loss.

curves of pure $\mathrm{PI}$ and $\mathrm{PI} / \mathrm{V}_{2} \mathrm{O}_{5}$ hybrid film are shown in Fig. 5. The introduction of $\mathrm{V}_{2} \mathrm{O}_{5}$ causes a decrease in thermal stability of hybrid films, which could be attributed to the decomposition reaction of metal oxide occurred during the PI imidization reaction step $[16,17]$. And the ether group of ODA component possessing unpaired electron will induce the oxidation reaction of PI film and hence lower the thermal stability.

Fig. 6 is the storage modulus curves of pure $\mathrm{PI}$ and $\mathrm{PI} / \mathrm{V}_{2} \mathrm{O}_{5}$ hybrid films changing with temperature. The storage modulus of hybrid films are all larger than pure PI and increased as the $\mathrm{V}_{2} \mathrm{O}_{5}$ content is with $6 \mathrm{wt} . \%$, while the storage modulus decreases as the $\mathrm{V}_{2} \mathrm{O}_{5}$ content is with 10 wt. $\%$.

The reason could be attributed to the $6 \mathrm{wt} . \%$ $\mathrm{V}_{2} \mathrm{O}_{5}$ content, which induces that the molecular structure to become more rigid. While as the $\mathrm{V}_{2} \mathrm{O}_{5}$ content increases up to $10 \mathrm{wt} . \%$, the compatibility between polyimide and $\mathrm{V}_{2} \mathrm{O}_{5}$ decreased and the microstructure defected. This will induce the decrease of storage modulus. Fig. 7 and Table 2 show the effect of temperature on the Tan Delta curves. And the Tan $\delta$ values of pure PI and the $T_{\mathrm{g}}$ values are increased with the increase of $\mathrm{V}_{2} \mathrm{O}_{5}$ content. The reason is that the crosslinked structure formed by the addition of $\mathrm{V}_{2} \mathrm{O}_{5}$, which will hinder the rotation and mobility of polyimide

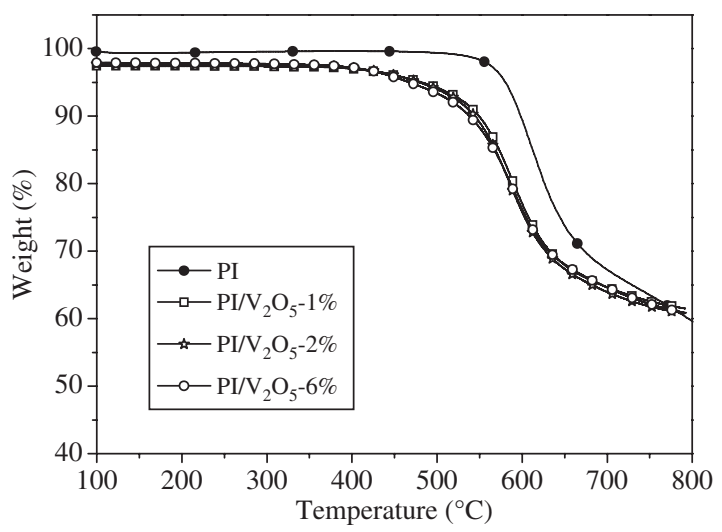

Fig. 5. Thermogram of pure $\mathrm{PI}$ and $\mathrm{PI} / \mathrm{V}_{2} \mathrm{O}_{5}$ hybrid film with different $\mathrm{V}_{2} \mathrm{O}_{5}$ content.

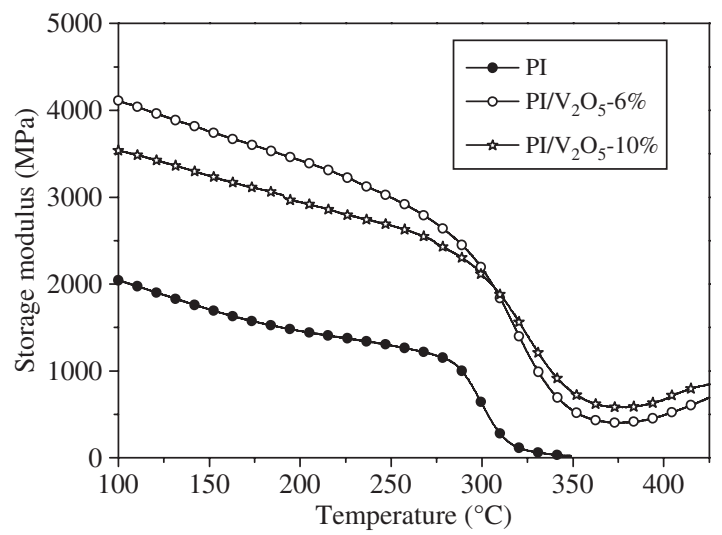

Fig. 6. Storage modulus curves of pure PI and $\mathrm{PI} / \mathrm{V}_{2} \mathrm{O}_{5}$ hybrid films change with temperature.

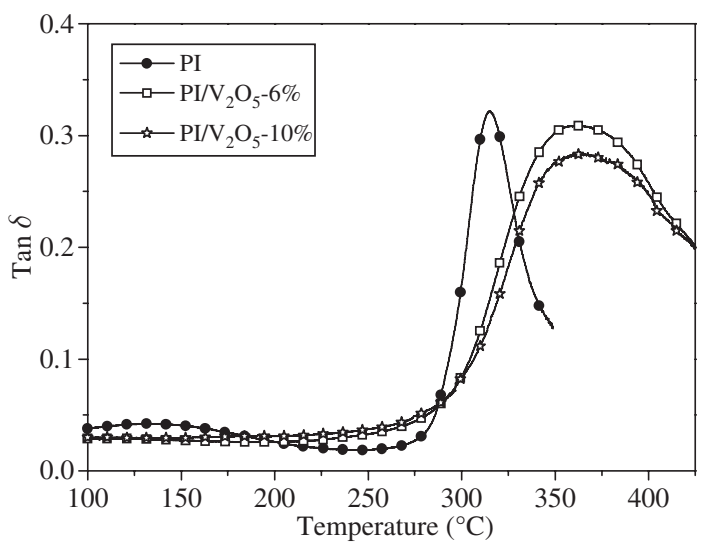

Fig. 7. Tan $\delta$ curves of pure $\mathrm{PI}$ and $\mathrm{PI} / \mathrm{V}_{2} \mathrm{O}_{5}$ hybrid films. 
Table 2

The glass transition temperature and storage modulus of $\mathrm{PI} / \mathrm{V}_{2} \mathrm{O}_{5}$ hybrid films

\begin{tabular}{lll}
\hline $\begin{array}{l}\text { Compound } \\
\text { code }\end{array}$ & $\begin{array}{l}\text { Storage modulus } \\
(\mathrm{MPa})\end{array}$ & $\begin{array}{l}\text { Temperature }\left({ }^{\circ} \mathrm{C}\right) \\
\text { of Tan } \delta \text { peak }\end{array}$ \\
\hline $\mathrm{PI}$ & 2042 & 314.6 \\
$\mathrm{PI} / \mathrm{V}_{2} \mathrm{O}_{5}-6 \%$ & 4107 & 361.8 \\
$\mathrm{PI} / \mathrm{V}_{2} \mathrm{O}_{5}-10 \%$ & 3548 & 364.0 \\
\hline
\end{tabular}

molecular chain. And then induce the $T_{\mathrm{g}}$ values increase with the increase of $\mathrm{V}_{2} \mathrm{O}_{5}$ content for $\mathrm{PI} / \mathrm{V}_{2} \mathrm{O}_{5}$ hybrid polymer.

\section{Conclusions}

Polyimide containing $\mathrm{V}_{2} \mathrm{O}_{5}$ has been successfully prepared by sol-gel method. There is an obvious absorption peaks of $\mathrm{V}_{2} \mathrm{O}_{5}$ in the range of $700-430 \mathrm{~cm}^{-1}$. The intensity of absorption peak is increased with $\mathrm{V}_{2} \mathrm{O}_{5}$ content. Based on SEM result, the fractured cross-section surface roughness of the hybrid film also increases with $\mathrm{V}_{2} \mathrm{O}_{5}$ content. The incorporation of $\mathrm{V}_{2} \mathrm{O}_{5}$ causes a decrease in thermal stability of hybrid films. However, the hybrid films still possess good thermal property. According to the results of DMA study, the storage modulus of the hybrid films is reinforced with addition of $\mathrm{V}_{2} \mathrm{O}_{5}$. It also points that the addition of $\mathrm{V}_{2} \mathrm{O}_{5}$ shows higher $T_{\mathrm{g}}$ as compared with pure PI. Besides, the existence of $\mathrm{V}_{2} \mathrm{O}_{5}$ and amorphous morphology of hybrids can be indicated by X-ray detection.

\section{Acknowledgements}

The authors would like to express their appreciation to the Nation Science Council of the Republic of China for financial support for this study under grant NSC-95-2622-E-167-007-CC3 and Metal Industries Research \& Development Centre for the financial support.

\section{References}

[1] M. Ponzi, C. Duschatzky, A. Carrascull and E. Ponzi, Obtaining benzaldehyde via promoted $\mathrm{V}_{2} \mathrm{O}_{5}$ catalysts, Appl. Catal. A, 169 (1998) 373-379.

[2] P. Poizot, S. Grugeon, L. Dupont and J.M. Tarascon, Nano-sized transition-metal oxides as negativeelectrode materials for lithium-ion batteries, Nature, 407 (2000) 496-499.

[3] C.G. Granqvist, Handbook of inorganic electrochromic materials, Elsevier Science, Amsterdam, 1995.

[4] A. Talledo and C.G. Granqvist, Electrochromic vanadium-pentoxide-based films: structural, electrochemical, and optical properties, J. Appl. Phys., 77 (1995) 4655-4666.

[5] J. Livage, Vanadium pentoxide gels, Chem. Mater., 3 (1991) 578-593.

[6] G. Micocci, A. Serra, A. Tepore, S. Capone, R. Rella and P. Siciliano, Properties of vanadium oxide thin films for ethanol sensor, J. Vac. Sci. Technol. A, 15 (1997) 34-38.

[7] G. Gu, M. Schmidt, P.W. Chiu, A. Minett, J. Fraysse, G.T. Kim, S. Roth, M. Kozlov, E. Munoz and R. Baughman, $\mathrm{V}_{2} \mathrm{O}_{5}$ nanofibre sheet actuators, Nat. Mater., 2 (2003) 316-319.

[8] J.F. Xu, R. Czerw, S. Webster, D.L. Carroll, J. Ballato and R. Nesper, Nonlinear optical transmission in $\mathrm{VO}_{\mathrm{x}}$ nanotube composites, Appl. Phys. Lett., 81 (2002) 1711.

[9] A. Talledo, A.M. Anderson and C.G. Granqvist, Electrochemically lithiated $\mathrm{V}_{2} \mathrm{O}_{5}$ films. An optically passive ion storage for transparent electrochromic devices, J. Mater. Res., 6 (1990) 1253-1256.

[10] N. Gharbi, S. Sanches, J. Livage and J. Lemerle, Mixed-valence polyvanadic acid gels, Inorg. Chem., 21 (1982) 2758-2765.

[11] N. Ozer, Electrochemical properties of sol-gel deposited vanadium pentoxide films, Thin Solid Films, 305 (1997) 80-87.

[12] X. Wang, X. Chen, L. Gao, H. Zheng, M. Ji, T. Shen and Z. Zhang, Citric acid-assisted sol-gel 
synthesis of nanocrystalline $\mathrm{LiMn}_{2} \mathrm{O}_{4}$ spinel as cathode material, J. Cryst. Growth, 256 (2003) 123-127.

[13] P.C. Chiang, W.T. Whang and M.H. Tsai, Physical and mechanical properties of polyimide/titania hybrid films, Thin Soild Films, 447 (2004) 359-364.

[14] P.C. Chiang, W.T. Whang, S.C. Wu and K.R. Chuang, Effects of titania content and plasma treatment on the interfacial adhesion mechanism of nano titania-hybridized polyimide and copper system, Polymer, 45 (2004) 4465-4472.

[15] M.H. Tsai, S.J. Liu and P.C. Chiang, Synthesis and characteristics of polyimide/titania nano hybrid films, Thin Soild Films, 515 (2006) 1126-1131.

[16] M.H. Tsai and C.J. Ko, In situ formation, surface characteristics, and interfacial adhesion of poly(imide siloxane)/tantalum oxide hybrid films, Surf. Coat. Technol., 201 (2006) 4367-4371.
[17] C.J. Brinker and G.W. Sherrer, Sol-gel science, the physics and chemistry of sol-gel processing, Academic Press, San Diego, 1990.

[18] M.H. Tsai and W.T. Whang, Low dielectric polyimide/poly(silsesquioxane)-like nanocomposite material, Polymer, 42 (2001) 4197-4207.

[19] M.H. Tsai, P.C. Chiang, W.T. Whang, C.J. Ko and S.L. Huang, Synthesis and characteristics of polyimide/siloxane hybrid films for reliability adhesion, Surf. Coat. Technol., 200 (2006) 3297-3302.

[20] S.C. Hsu, W.T. Whang, C.H. Hung, P.C. Chiang and Y.N. Hsiao, Effect of the polyimide structure and $\mathrm{ZnO}$ concentration on the morphology and characteristics of polyimide/ZnO nanohybrid films, Macromol. Chem. Phys., 206 (2005) 291-298. 